\title{
Betel Nut Usage Is a Major Risk Factor for Coronary Artery Disease
}

\author{
Muhammad Shahzeb Khan ${ }^{1}$, Faizan Imran Bawany ${ }^{1}$, Muhammad Umer Ahmed ${ }^{2}$, \\ Mehwish Hussain ${ }^{1}$, Asadullah $\mathrm{Khan}^{3}$ \& Muhammad Nawaz Lashari ${ }^{3}$ \\ ${ }^{1}$ Dow Medical College, Pakistan \\ ${ }^{2}$ Ziauddin Medical University, Pakistan \\ ${ }^{3}$ Civil Hospital, Pakistan \\ Correspondence: Muhammad Shahzeb Khan, 109/2 Main Khayabane Amir Khusro Phase 6 DHA, Karachi, \\ Pakistan. Tel: 92-321-206-6743. E-mail: shahzebkhan@gmail.com
}

Received: November 17, 2013 Accepted: December 11, 2013 Online Published: December 27, 2013

doi:10.5539/gjhs.v6n2p189 URL: http://dx.doi.org/10.5539/gjhs.v6n2p189

\begin{abstract}
Aim: The objective of our study was to assess betel nut usage as one of the major risk factors associated with coronary artery disease.

Methods: This case control study consisted of 300 controls and 300 cases. A structured questionnaire was administered to the participants to assess consumption of betel nut and confounding variables. A respondent was considered a regular consumer of betel nut if he/she consumed one or more pieces of betel nut every day for a period of greater than 6 months.
\end{abstract}

Results: About 8 in 10 betel nut chewers developed coronary artery disease. After adjusting for diabetes and hypertension, the odds ratio analysis depicted 7.72 times greater likelihood for coronary artery disease in patients who chewed betel nut for more than 10 years.

Conclusion: Our study concludes that betel nut chewing is a significant risk factor leading to the development of coronary artery disease.

Keywords: betel nut, coronary artery disease, risk factor, Karachi, Pakistan

\section{Introduction}

Betel nut chewing is classified as the fourth major source of addiction and abuse worldwide with betel nut chewers now contributing to greater than $10 \%$ of the total worldwide population (Boucher \& Mannan, 2002; Gupta \& Warnakulasuriya, 2002). It is approximated that aroundsix hundred million people chew betel nut worldwide (Pankaj, 2010). The practice of betel nut chewing is prevalent especially in Asian countries such as Pakistan, India, Bangladesh, Sri Lanka, and Indonesia and also in regions where betel chewing communities tend to migrate (Boucher \& Mannan, 2002; Gupta \& Warnakulasuriya, 2002).

Betel nut chewing has been found to be associated with an increased risk of hepatocellular carcinoma (Tsai, Jeng, \& Chuang, 2004), oral (Zhang \& Reichart, 2007) and esophageal cancer (Wu et al., 2006) and liver cirrhosis (Hsiao, Liao, Hsieh, \& Wong, 2007). In addition, a strong association of betel nut chewing with obesity, hypertension, type 2 diabetes, hyperlipidemia, chronic kidney disease and metabolic syndrome has also been established (Chang et al., 2006; Yen et al., 2006; Tung et al., 2004; Kang et al., 2007). These findings therefore imply an increased propensity towards the development of coronary artery disease [CAD] with betel nut chewing.

Cardiovascular diseases contribute to more than 15 million deaths annually worldwide (WHO, 1999) with Pakistan alone contributing to 410/100000 of the mortalities due to CAD (Samad et al., 1992). Studies have established that people of the Indo Asian origin show the greatest susceptibility towards CAD (Gupta et al., 2006); therefore CAD is classified as the chief cause of mortality in the South Asian countries such as Pakistan. Despite the fact that these deaths could be avoided by simple measures such as healthy diet, avoiding tobacco and regular physical activity, the numbers are still seen to be rising and costing up to 200000 deaths from CAD in Pakistan annually (The News, 2012).

Furthermore, a strong involvement of inflammatory markers of cardiovascular disease such as matrix 
metalloproteinase 9 and C-reactive protein with betel nut chewing has also been highlighted in a few studies (Timms et al., 2002). Extensive literature review shows that few studies have focused on betel nut chewing as a significant factor causing CAD. Since both betel nut chewing and CAD are prevalent worldwide, we conducted a case control study to further establish an association of betel nut chewing as a major risk factor for CAD.

\section{Methods}

This case control study was approved by the Institutional Review Board and Ethical Committee of Dow University of Health Sciences. Informed written consent was taken from each participant and they were assured about confidentiality of their data. The sample population was collected over a period of six months from January 2013 to June 2013. CAD patients were selected from registry of Cardiology department, Civil Hospital Karachi. As a government hospital, it offers low cost cardiac care within reach of patients with diverse socioeconomic status. A sample of 300 cases of coronary heart disease and 300 controls was selected in order to establish a relationship, if any, between betel nut chewing and CAD. Control samples primarily consisted of individuals who were diagnosed negative for CAD by cardiologists in the same time span as the case patients. The controls did not have a past history of ischemic heart disease or coronary heart disease. It should be highlighted that a high proportion of peoplewith chest pain and shortness of breath visit cardiac centers to rule out cardiac disease either due to self-referral or referral by a general physician. Some controls were diagnosed for non-specific chest pain and gastric hyperacidity. A small number of patients were not given any diagnosis and symptoms of chest pain or shortness of breath were written in patient notes.

Sample was collected using the following inclusion criteria: age must be $40-75$ years and must be a non-smoker and non-alcoholic. Smokers were said to be regular consumers if they smoked 10 cigarettes or more every day for a period of greater than 6 months. Smokers were excluded from the study as we wanted a relationship of specifically betel nut chewing and CAD. Similarly, drinkers were considered as regular consumers if they consumed alcohol more than once a week for greater than 6 months. Diagnosis for the patients was based on positive classical symptoms and positive diagnostic tests such as electrocardiogram, cardiac enzyme, exercise tolerance test and coronary artery angiogram. Exercise tolerance test was considered positive if there was a ST segment elevation or depression of $>1 \mathrm{~mm}$ in 3 consecutive P-QRS-T complexes in 2 or $>2$ consecutive leads. Results of angiogram were analyzed by two experienced cardiologist. When there was conflict of diagnosis of CAD between the cardiologists, opinion of a third cardiologist was sought for final diagnosis.

A structured questionnaire was administered to the participants to assess consumption of betel nut and confounding variables. Participants were first presented a screening questionnaire to filter eligible cases and controls. This questionnaire covered basic demographic variables included age, gender, residence, smoking and alcohol status and heart disease status. Once eligibility of participants was confirmed, a questionnaire was administered to gather detailed information on betel nut usage, presence of other risk factors for coronary heart disease and socio-demographic information including marital status, education level, occupation and monthly earning as a substitution for economic status.

A respondent was considered a regular consumer of betel nut if he/she consumed one or more pieces of betel nut every day for a period of greater than 6 months. Further information was sought to determine when betel nut consumption started and the amount consumed every day. All types of betel nut consumption were included in the survey, including betel leaf (pan) or betel nuts alone. History of other conditions like hypertension, diabetes, stroke and CAD were also inquired. A consumer was considered a hypertensive if he/she had a history of hypertension or was currently taking antihypertensive drugs. A consumer was considered a diabetic if he/she had a history of diabetes, was on an oral sugar lowering agent or insulin therapy, or had a fasting glucose level> $126 \mathrm{mg} / \mathrm{dl}$.

IBM SPSS for Windows Software (SPSS, Chicago, IL, version 21) was used for statistical analyses. Characteristics and habits were presented in terms of frequencies and percentages. Chi-square test was performed to examine difference of proportions of demographic, clinical and betel nut's consumption pattern between cases and controls. Uni-variable analysis was performed to obtain odds ratio for cases and controls for consumption pattern of betel nut. Multi-variable analysis was used to attain adjusted odds ratio using hypertension and diabetes as confounding factors for betel nut chewers.

\section{Results}

A total of $300 \mathrm{CAD}$ cases were recruited in the study and equal numbers of healthy controls werealsotaken. Most of the cases $(n=273)$ and controls $(n=262)$ were married. Majority of participants in both groups had under primary (Cases: $48.4 \%$, Controls: $51.6 \%$ ) and secondary (Cases: $51.2 \%$, Controls: $48.8 \%$ ) education. Most of the cases and controls had low socio-economic status. The proportions of cases having low BMI $\left(<18.5 \mathrm{KG} / \mathrm{m}^{2}\right)$ 
was $40.90 \%$, normal BMI $\left(18.5-27 \mathrm{~kg} / \mathrm{m}^{2}\right) 50 \%$ and high BMI $\left(>27 \mathrm{~kg} / \mathrm{m}^{2}\right) 52 \%$. Their control counterparts had similar proportion on these different $\mathrm{BMI}$ ranges $(\mathrm{P}=0.41)$. The presence of CAD disease in family was almost equal in both the groups $(\mathrm{P}=0.704)$. Patients with hypertension were more likely to have CAD (Case: $\mathrm{n}=210$, 78.4\% v/s Control: $\mathrm{n}=58,21.6 \%$ : $\mathrm{P}<0.0001)$. Similarly, development of CAD in diabetic patient was significantly more as compare to a non-diabetic $(\mathrm{P}<0.0001)$ (Table 1$)$.

Table 1. Comparison of demographic variables between coronary artery disease cases and healthy controls

\begin{tabular}{|c|c|c|c|c|}
\hline & & CAD Patients $(n=300)$ & Healthy Controls $(n=300)$ & $P$ Value \\
\hline \multirow[t]{2}{*}{ Age } & $45-60$ & $120(50.60 \%)$ & $117(49.40 \%)$ & 0.802 \\
\hline & $>60$ & $180(49.60 \%)$ & $183(50.40 \%)$ & \\
\hline \multirow[t]{2}{*}{ Gender } & male & $210(51.5 \%)$ & $198(48.50 \%)$ & 0.294 \\
\hline & female & $90(46.90 \%)$ & $102(53.10 \%)$ & \\
\hline \multirow[t]{3}{*}{ Marital Status } & married & $273(51.00 \%)$ & $262(49.00 \%)$ & 0.14 \\
\hline & divorced & $9(56.30 \%)$ & $7(43.80 \%)$ & \\
\hline & widowed & $18(51.00 \%)$ & $31(49.00 \%)$ & \\
\hline \multirow{3}{*}{$\begin{array}{l}\text { Body Mass } \\
\text { Index }\end{array}$} & $<18.5$ & $18(40.90 \%)$ & $26(59.10 \%)$ & 0.41 \\
\hline & $18.5-27$ & $180(50.00 \%)$ & $180(50.00 \%)$ & \\
\hline & $>27$ & $102(52.00 \%)$ & $94(48.00 \%)$ & \\
\hline \multirow[t]{4}{*}{ Education } & Under Primary & $135(48.40 \%)$ & $144(51.6 \%)$ & 0.459 \\
\hline & secondary & $144(51.20 \%)$ & $137(48.8 \%)$ & \\
\hline & under graduate & $15(46.90 \%)$ & $17(53.10 \%)$ & \\
\hline & post graduate & $6(75.00 \%)$ & $2(25.00 \%)$ & \\
\hline \multirow{3}{*}{$\begin{array}{l}\text { Socioeconomic } \\
\text { Status }\end{array}$} & low & $180(47.10 \%)$ & $202(52.90 \%)$ & 0.164 \\
\hline & middle & $99(55.60 \%)$ & $79(44.40 \%)$ & \\
\hline & high & $21(52.50 \%)$ & $19(47.50 \%)$ & \\
\hline \multirow[t]{2}{*}{ Family History } & yes & $75(51.40 \%)$ & $71(49.60 \%)$ & 0.704 \\
\hline & no & $225(49.60 \%)$ & $229(50.40 \%)$ & \\
\hline \multirow[t]{2}{*}{ Hypertension } & No & $90(27.10 \%)$ & $242(72.90 \%)$ & $<0.0001$ \\
\hline & yes & $210(78.40 \%)$ & $58(21.60 \%)$ & \\
\hline \multirow[t]{2}{*}{ Diabetes } & no & $177(42.90 \%)$ & $236(57.10 \%)$ & $<0.0001$ \\
\hline & yes & $123(65.80 \%)$ & $64(34.20 \%)$ & \\
\hline
\end{tabular}

About 8 in 10 betel nut chewers developed CAD. The proportion of development of CAD was almost half among participants who did not chew betel nut. The crude odds ratio depicted 6.4 times greater chance of CAD if a person was a betel nut chewer. Participants who were chewing betel nut for more than 10 years, hadahigher chance of developing CAD (Crude OR: 8.16, 95\% CI $=3.51-18.95$ ). After adjusting for diabetes and hypertension, the odds ratio analysis depicted 7.72 times more likelihood of CAD in patients who had been chewing betel nut for more than 10 years. The patients who chewed more than 10 pieces a day were 4.31 times more likely to develop CAD. The adjusted odds ratio was not significantly different from the unadjusted ratio (Adj OR: 4.476, 95\% CI: 1.46-13.76) (Table 2). 
Table 2. Comparison of betel nut consumption between coronary artery disease cases and healthy controls

\begin{tabular}{|c|c|c|c|c|c|c|c|c|c|c|}
\hline & & Healthy Control & CAD Patients & $P$ Value & Crude OR & $95 \% \mathrm{CI}$ & & Adjusted OR* & $95 \% \mathrm{CI}$ & \\
\hline \multirow[t]{2}{*}{ Betel nut } & No & $266(61.29 \%)$ & $168(38.71 \%)$ & & & & & & & \\
\hline & Yes & $34(20.48 \%)$ & $132(79.52 \%)$ & $<0.0001$ & 6.401 & 4.192 & 9.774 & & & \\
\hline \multirow{2}{*}{$\begin{array}{l}\text { Time of } \\
\text { start }\end{array}$} & less than 10 years & $24(44.40 \%)$ & $30(55.60 \%)$ & & & & & & & \\
\hline & more than 10 years & $10(8.90 \%)$ & $102(91.10 \%)$ & $<0.0001$ & 8.16 & 3.514 & 18.95 & 7.718 & 2.357 & 21.86 \\
\hline \multirow[t]{2}{*}{ Amount } & less than 10 pieces a day & $19(38.80 \%)$ & $30(61.20 \%)$ & & & & & & & \\
\hline & more than 10 pieces a day & $15(12.80 \%)$ & $102(87.20 \%)$ & $<0.0001$ & 4.307 & 1.955 & 9.489 & 4.476 & 1.455 & 13.775 \\
\hline
\end{tabular}

* Adjusted for Hypertension and Diabetes.

\section{Discussion}

This is one of the few case control studies to illustrate the risk of betel nut chewing associated with CAD. After taking into account the known risk factors such as age, gender, BMI, family history of hypertension and diabetes, our study established that there was a significant risk of CAD associated with the habit of betel nut chewing amongst adults, specifically those who had been habitually chewing betel nut for more than 10 years and more than 10 pieces a day. Several other studies have also expressed this strong co-relation, however some of those studies were centered around men, in comparison to ours which illustrates the effects on both the genders (Lan et al., 2007; Lin et al., 2008; Yen et al., 2008; Guh, Chen, \& Tsai, 2007).

Many studies have also shown a strong relationship between smokeless tobacco use with risk factors for cardiovascular diseases like hypertension and deranged lipid profiles. However, the results assessing the association between smokeless tobacco and cardiovascular diseases are not consistent (Boffeta et al., 2009; Rahman, Mahmood, \& Spurrier, 2011). Many cohort studies (Bolinder et al., 1994; Henley et al., 2005; Yatsuya \& Folsom, 2010) and some case control studies (Teo et al., 2006; Rahman \& Zaman, 2008), have shown a strong positive association. In comparison, other cohort (Accortt et al., 2002; Hansson, Pederson, \& Galanti, 2009; Janzon \& Hedblad, 2009) and case control studies (Huhtasaari et al., 1992; Huhtasaari et al., 1999; Hergens et al., 2005) have not yet established such an association. Some studies carried out in the western part of the world have found a significant association (Bolinder et al., 1994; Henley et al., 2005) while others have not (Accortt et al., 2002; Hansson et al., 2009; Janzon \& Hedblad, 2009). However, most of the studies in South Asian countries have highlighted the positive association. This could be attributed to the fact that South Asian smokeless tobacco products differ from western products in terms of constituents and are mostly used in conjunction with betel nut. Therefore, it can strongly be proposed that the reason for cardiovascular diseases in smokeless tobacco users could be attributed to betel nut. The strong impact of betel nut chewing in the subsequent development of CAD is highlighted by our research which found that almost 8 out of 10 betel nut chewers developed CAD.

According to a research carried out amongst older individual adults, people who had the habit of chewing betel nut were at a significantly increased risk of cerebrovascular disease and mortality hazard ratio (HR $=1.66,95 \%$ CI: 1.19, 2.30) compared to those who did not (Lan et al., 2007). Another study established that there was a dose dependantrelationship between betel nut chewing and CAD (Tsai et al., 2012). This fact is consistent with our research which also showed that people who chewed more than 10 pieces of betel nut a day were 4.31 times more likely to get CAD in comparison to those who did not. Previously, chewing betel nut had been found to be the cause of many risk factors for CAD. One study established that chewing betel nut was associated with central obesity (Lin et al., 2009). However, our study did not find an association between betel nut chewing and obesity, keeping body Mass Index as a measure of obesity.

According to a research by Tseng et al. (2008), betel nut chewing was strongly linked with hypertension in patients with type 2 diabetes mellitus.Another study established a positive association between betel nut chewing and metabolic syndrome (Guh et al., 2006). These facts are consistent with our research which found diabetes and hypertension to be significantly associated with a risk of CAD in patients chewing betel nut. It can therefore be proposed that chewing betel nut may either be an independent factor associated with CAD or be a factor by influencing known risk factors for hypertension or diabetes.

There are many mechanisms which could help explain the missing links among betel nut chewing, atherosclerosis and CAD. Acreoline, the compound found in betel nut, has been reported to cause induction of COX-2 expression and increasing TIMP levels in studies done in vitro (Tsai et al., 2003). The compound hydroxychavicol was found to induce the production of reactive oxygen species and thereby mediating cell 
damage (Iverson et al., 1995). Another study established that the expression of IL-1 beta, IL8, IL 6 and tumor necrosis factor increased in human mononuclear cells after being treated with the extract of betel nut (Chang et al., 2009). Furthermore, the extracts of betel nut and quid have found to increase the cytotoxic effects on oxidized LDL towards aortic endothelial cells (Owen et al., 2007). These facts help propose that the reason for CAD in betel nut chewing individuals could be specifically attributed to atherosclerosis.

Although we have established that chewing betel nut was associated with a significant risk of CAD, our study has certain limitations. Firstly, the questionnaires lacked details about the type of preparation used and whether betel nut was chewed alongwith a combination of different compounds. Secondly, the study does not establish that as to which specific branch of the coronary artery was more affected in this habit. However, our study has highlighted a significant issue of betel nut chewing being a major risk factor for one of the most common diseases worldwide.

\section{Conclusion}

Our study concludes that betel nut chewing is a significant risk factor for the development of CAD. It was found that betel nut chewing increased the likelihood of CAD by almost 6times. Furthermore, it was also established that those who had been chewing betel nut for more than 10 years had an 8 fold increase in the risk of developing CAD. This shows that long term betel nut chewing should be considered a significantly important risk factor along with hypertension and diabetes for CAD. However, further clinical studies should be conducted to explore the exact pathogenesis of betel nut chewing causing CAD.

\section{References}

Accortt, N. A., Waterbor, J. W., Beall, C., \& Howard, G. (2002). Chronic disease mortality in a cohort of smokeless tobacco users. Am J Epidemiol, 156, 730-737. http://dx.doi.org/10.1093/aje/kwf106

Boffetta, P., \& Straif, K. (2009). Use of smokeless tobacco and risk of myocardial infarction and stroke: systematic review with meta-analysis. $B M J, 339,3060$. http://dx.doi.org/10.1136/bmj.b3060

Bolinder, G., Alfredsson, L., Englund, A., \& de Faire, U. (1994). Smokeless tobacco use and increased cardiovascular mortality among Swedish construction workers. Am J Public Health, 84, 399-404. http://dx.doi.org/10.2105/AJPH.84.3.399

Boucher, B. J., \& Mannan, N. (2002). Metabolic effects of the consumption of Areca catechu. Addict Biol, 7 , 103-10. http://dx.doi.org/10.1080/13556210120091464

Chang, L. Y., Wan, H. C., Lai, Y. L., Kuo, Y. F., Liu, T. Y., \& Chen, Y. T. (2009). Areca nut extracts increased expression of inflammatory cytokines, tumor necrosis factor- $\alpha$, interleukin- $1 \beta$, interleukin- 6 and interleukin-8, in peripheral blood mononuclear cells. $J$ Periodontal Res., 44(2), 175-83. http://dx.doi.org/10.1111/j.1600-0765.2008.01104.x

Chang, W. C., Hsiao, C. F., Chang, H. Y., Lan, T. Y., Hsiung, C. A., Shih, Y. T., \& Tai, T. Y. (2006). Betel nut chewing and other risk factors associated with obesity among Taiwanese male adults. Int J Obes (Lond), 30, 359-63. http://dx.doi.org/10.1038/sj.ijo.0803053

Guh, J. Y., Chen, H. C., Tsai, J. F., \& Chuang, L. Y. (2007). Betel-quid use is associated with heart disease in women. Am J ClinNutr, 85, 1229-1235.

Guh, J. Y., Chuang, L. Y., \& Chen, H. C. (2006). Betel-quid use is associated with the risk of the metabolic syndrome in adults. Am J Clin Nutr, 83, 1313-1320.

Gupta, M., Singh, N., \&Verma, S. (2006). South Asians and cardiovascular risk: what clinicians should know. Circulation, 113, 924-9. http://dx.doi.org/10.1161/CIRCULATIONAHA.105.583815

Gupta, P. C., \& Warnakulasuriya, S. (2002). Global epidemiology of areca nut usage. Addict Biol, 7, 77-83. http://dx.doi.org/10.1080/13556210020091437

Hansson, J., Pedersen, N. L., Galanti, M. R., Andersson, T., Ahlbom, A., Hallqvist, J., \& Magnusson, C. (2009). Use of snus and risk for cardiovascular disease: results from the Swedish Twin Registry. J Intern Med, 265, 717-724. http://dx.doi.org/10.1111/j.1365-2796.2009.02081.x

Henley, S. J., Thun, M. J., Connell, C., \& Calle, E. E. (2005). Two large prospective studies of mortality among men who use snuff or chewing tobacco (United States). Cancer Cause Control, 16, 347-358. http://dx.doi.org/10.1007/s10552-004-5519-6

Hergens, M. P., Ahlbom, A., Andersson, T., \& Pershagen, G. (2005). Swedish moist snuff and myocardial infarction among men. Epidemiology, 16, 12-16. http://dx.doi.org/10.1097/01.ede.0000147108.92895.ba 
Hsiao, T. J., Liao, H. W., Hsieh, P. S., \& Wong, R. H. (2007). Risk of betel quid chewing on the development of liver cirrhosis: a community-based case-control study. Ann Epidemiol, 17, 479-85. http://dx.doi.org/10.1016/j.annepidem.2006.12.007

Huhtasaari, F., Asplund, K., Lundberg, V., Stegmayr, B., \& Wester, P. O. (1992). Tobacco and myocardial infarction: is snuff less dangerous than cigarettes? BMJ, 305, 1252-1256.

Huhtasaari, F., Lundberg, V., Eliasson, M., Janlert, U., \& Asplund, K. (1999). Smokeless tobacco as a possible risk factor for myocardial infarction: a population-based study in middle-aged men. $J$ Am Coll Cardiol, 34, 1784-1790. http://dx.doi.org/10.1016/S0735-1097(99)00409-X

Iverson, S. L., Hu, L. Q., Vukomanovic, V., \& Bolton, J. L. (1995). The influence of the p-alkyl substituent on the isomerization of o-quinones to p-quinonemethides: potential bioactivation mechanism for catechols. Chem Res Toxicol, 8, 537-544. http://dx.doi.org/10.1021/tx00046a007

Janzon, E., \& Hedblad, B. (2009). Swedish snuff and incidence of cardiovascular disease. A population-based cohort study. BMC Cardiovasc Disord, 9, 21. http://dx.doi.org/10.1186/1471-2261-9-21

Kang, I. M., Chou, C. Y., Tseng, Y. H., Huang, C. C., Ho, W. Y., Shih, C. M., \& Chen, W. (2007). Association between betel nut chewing and chronic kidney disease in adults. J Occup Environ Med, 49, 776-9. http://dx.doi.org/10.1097/JOM.0b013e318095a48a

Lan, T. Y., Chang, W. C., Tsai, Y. J., Chuang, Y. L., Lin, H. S., \& Tai, T. Y. (2008). Areca nut chewing and mortality in an elderly cohort study. Am J Epidemiol, 165, 677-683. http://dx.doi.org/10.1093/aje/kwk056

Lin, W. Y., Chiu, T. Y., Lee, L. T., Lin, C. C., Huang, C. Y., \& Huang, K. C. (2008). Betel nut chewing is associated with increased risk of cardiovascular disease and all-cause mortality in Taiwanese men. Am J Clin Nutr, 87, 1204-1211.

Lin, W. Y., Pi-Sunyer, F. X., Liu, C. S., Li, T. C., Li, C. I., Huang, C. Y., \& Lin, C. C. (2009). Betel nut chewing is strongly associated with general and central obesity in Chinese male middle-aged adults. Obesity (Silver Spring), 17, 1247-1254.

Owen, P. L., Matainaho, T., Sirois, M., \& Johns, T. (2007). Endothelial cytoprotection from oxidized LDL by some crude melanesian plant extracts is not related to their antioxidant capacity. J Biochem Mol Toxicol, 21, 231-242. http://dx.doi.org/10.1002/jbt.20186

Pankaj, C. (2010). Areca Nut or Betel Nut Control is Mandatory if India Wants to Reduce the Burden of Cancer Especially Cancer of Oral Cavity. Jaypee Journals, 1, 17-20.

Qasim, M. (2012). Cardiovascular diseases claim 200,000 lives annually in Pakistan. International The News.

Rahman, M. A., \& Zaman, M. M. (2008). Smoking and smokeless tobacco consumption: possible risk factors for coronary heart disease among young patients attending a tertiary care cardiac hospital in Bangladesh. Public Health, 122, 1331-1338. http://dx.doi.org/10.1016/j.puhe.2008.05.015

Rahman, M. A., Mahmood, M. A., Spurrier, N., Rahman, M., \& Leeder, S. (2011). A systematic review of epidemiological studies on the association between smokeless tobacco use and coronary heart disease. $J$ Public Health Epidemiol, 3, 593-603.

Samad, A., Sahibzada, W. A., \& Mattu, A. (1992). Risk factor analysis in a random population of 4 cities in Pakistan. Pakistan J Cardiol, 3, 7-14.

Teo, K. K., Ounpuu, S., Hawken, S., Pandey, M. R., Valentin, V., Hunt, D., ... Yusuf, S., INTERHEART Study Investigators. (2006). Tobacco use and risk of myocardial infarction in 52 countries in the INTERHEART study: a case-control study. Lancet, 368, 647-658. http://dx.doi.org/10.1016/S0140-6736(06)69249-0

Timms, P. M., Mannan, N., Hitman, G. A., Noonan, K., Mills, P. G., Syndercombe-Court, D., ... Boucher, B. J. (2002). Circulating MMP9, vitamin D and variation in the TIMP-1 response with VDR genotype: mechanisms for inflammatory damage in chronic disorders? QJM, 95, 787-96. http://dx.doi.org/10.1093/qjmed/95.12.787

Tsai, C. H., Chou, M. Y., \& Chang, Y. C. (2003). The up-regulation of cyclooxygenase-2 expression in human buccal mucosal fibroblasts by arecoline: a possible role in the pathogenesis of oral submucousfibrosis. $J$ Oral Pathol Med, 32, 146-153. http://dx.doi.org/10.1034/j.1600-0714.2003.00004.x

Tsai, J. F., Jeng, J. E., \& Chuang, L.Y. (2004). Habitual betel quid chewing and risk for hepatocellular carcinoma complicating cirrhosis. Medicine, 83, 176-87. http://dx.doi.org/10.1097/01.md.0000126971.80227.a4 
Tsai, W. C., Wu, M. T., Wang, G. J., Lee, K. T., Lee, C. H., Lu, Y. H., ... Lai, W. T. (2012). Chewing areca nut increases the risk of coronary artery disease in Taiwanese men: a case-control study. BMC Public Health, 12, 162. http://dx.doi.org/10.1186/1471-2458-12-162

Tseng, C. H. (2008). Betel nut chewing is associated with hypertension in Taiwanese type 2 diabetic patients. Hypertens Res, 31, 417-423. http://dx.doi.org/10.1291/hypres.31.417

Tung, T. H., Chiu, Y. H., Chen, L. S., Wu, H. M., Boucher, B. J., \& Chen, T. H. (2004). A population-based study of the association between areca nut chewing and type 2 diabetes mellitus in men (Keelung Community-based Integrated Screening Programme no. 2). Diabetologia, 47, 1776-81. http://dx.doi.org/10.1007/s00125-004-1532-2

World Health Organization. (1999). The world health-report 1999: making a difference in people's lives: achievements and challenges. Geneva, WHO.

Wu, I. C., Lu, C. Y., Kuo, F. C., Tsai, S. M., Lee, K. W., Kuo, W. R., \& Ko, Y. C. (2006). Interaction between cigarette, alcohol and betel nut use on esophageal cancer risk in Taiwan. Eur J Clin Invest, 36, 236-41. http://dx.doi.org/10.1111/j.1365-2362.2006.01621.x

Yatsuya, H., \& Folsom, A. R. (2010). Risk of incident cardiovascular disease among users of smokeless tobacco in the Atherosclerosis Risk in Communities (ARIC) study. Am $J$ Epidemiol, 172, 600-605. http://dx.doi.org/10.1093/aje/kwq191

Yen, A. M., Chen, L. S., Chiu, Y. H., Boucher, B. J., \& Chen, T. H. (2008). A prospective community-population-registry based cohort study of the association between betel-quid chewing and cardiovascular disease in men in Taiwan (KCIS no. 19). Am J Clin Nutr, 87, 70-78.

Yen, A. M., Chiu, Y. H., Chen, L. S., Wu, H. M., Huang, C. C., Boucher, B. J., \& Chen, T. H. (2006). A population-based study of the association between betel-quid chewing and the metabolic syndrome in men. Am J Clin Nutr, 83, 1153-60.

Zhang, X., \& Reichart, P. A. (2007) A review of betel quid chewing, oral cancer and pre cancer in Mainland China. Oral Oncol, 43, 424-30. http://dx.doi.org/10.1016/j.oraloncology.2006.08.010

\section{Copyrights}

Copyright for this article is retained by the author(s), with first publication rights granted to the journal.

This is an open-access article distributed under the terms and conditions of the Creative Commons Attribution license (http://creativecommons.org/licenses/by/3.0/). 